\title{
Synergistic Copper/Palladium Catalysis for the Regio- and Stereose- lective Synthesis of Borylated Skipped Dienes
}

\author{
Jaime Mateos, Eva Rivera-Chao and Martín Fañanás-Mastral* \\ Centro Singular de Investigación en Química Biolóxica e Materiais Moleculares (CIQUS), Departamento de Química Orgá- \\ nica, Universidade de Santiago de Compostela, 15782 Santiago de Compostela, Spain
}

\begin{abstract}
A Cu/Pd-catalyzed allylboration of alkynes with allyl carbonates and bis(pinacolato)diboron to afford borylated skipped dienes is reported. Synergistic $\mathrm{Cu}$ and Pd catalysis enables this protocol to work for a wide array of alkynes and allyl carbonates under mild conditions with total regio- and stereocontrol. This transformation features the catalytic generation of $\beta$ borylalkenylcopper intermediates and their use in Pd-catalyzed allylic substitution of allyl carbonates. The utility of this method is highlighted by the synthesis of $(Z, E)$ - $\alpha$-homofarnesene (pheromone) and the terpenoid precursor of Merochlorins (potent antibiotic agents).
\end{abstract}

\section{KEYWORDS: Synergistic catalysis, copper, palladium, multicomponent reactions, skipped dienes}

1,4-Dienes, so called skipped dienes, are common structural motifs in numerous biologically active natural compounds in which the stereochemical identity of the diene unit imparts unique properties. ${ }^{1}$ Consequently, general methods that allow for the efficient and stereoselective preparation of skipped dienes are in high demand. Among the catalytic methodologies available for the synthesis of these important molecules, ${ }^{2}$ transition metal-catalyzed allylic substitution using alkenylmetal reagents has become a powerful tool. ${ }^{3-5}$ Great advance has been made in this field and nowadays selective protocols based on palladium, ${ }^{3}$ copper $^{4}$ and iridium ${ }^{5}$ catalysis are available. However, these methodologies involve the preparation and use of stoichiometric amounts of basic alkenylmetal reagents. The high reactivity of most of these organometallic reagents imposes limitations with respect to the functional-group tolerance and examples involving the use of functionalized alkenylmetal reagents are scarce. ${ }^{4 \mathrm{e}}$ In this context, a catalytic method for stereoselective allylic substitution using simple alkynes as transient functionalized alkenylmetal species would circumvent these issues and greatly expand the scope of stereodefined skipped dienes.

Borylcopper complexes can add across an alkyne to generate nucleophilic $\beta$-borylalkenylcopper species. ${ }^{6}$ These organocopper intermediates can react in a catalytic fashion by protonation with alcohols to afford formal hydroboration products ${ }^{7}$ or with carbon electrophiles in carboboration reactions. ${ }^{8-12}$ To develop a regio- and stereoselective catalytic methodology for the synthesis of skipped dienes using alkynes as latent alkenylmetal equivalents, we questioned whether a $\beta$ borylalkenylcopper intermediate could be generated catalytically and exploited in a Pd-catalyzed allylic substitution under synergistic catalysis (Scheme 1). ${ }^{13-15}$ The combination of $\mathrm{Cu}$ and Pd catalysis would allow for concomitant activation of both the alkyne and the allyl substrate and provide total control over the different selectivity factors associated to this transformation, giving access to regio- and stereodefined skipped dienes bearing a Bpin group which can be further functionalized.

Scheme 1. Synthesis of borylated skipped dienes via $\mathrm{Cu} / \mathrm{Pd}$-catalyzed allylboration of alkynes

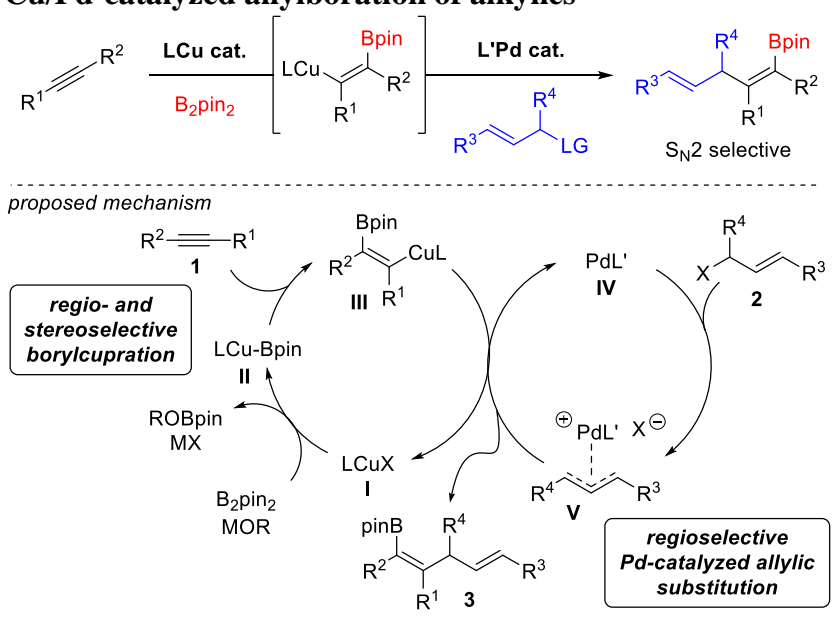

In our proposed dual catalytic mechanism (Scheme 1), a regio- and stereoselective borylcupration of the alkyne $\mathbf{1}$ with LCu-Bpin complex II would catalytically generate $\beta$-borylalkenylcopper(I) intermediate III. In the second catalytic cycle, a cationic $\pi$-allyl $\operatorname{Pd}($ II) complex $\mathbf{V}$ would be formed by oxidative addition of an allyl substrate to a $\operatorname{Pd}(0)$ complex IV. Reaction between intermediates III and $\mathbf{V}$, in which the palladium catalyst controls the regioselectivity of the allylic substitution, ${ }^{16}$ would connect both cycles with formation of the borylated skipped diene $\mathbf{3}$ and regeneration of both catalysts I and IV. Besides the challenging control of the regio- and stereoselectivity, success of our proposed strategy also requires a high level of chemoselectivity as competitive addition of $\mathrm{B}_{2} \mathrm{pin}_{2}$ to the allyl substrate, which has been described to 
proceed either under copper ${ }^{17}$ and palladium ${ }^{18}$ catalysis, has to be suppressed. Herein, we describe the successful implementation of this idea and thus the development of a threecomponent catalytic process which allows for the regio-, stereo- and chemoselective synthesis of borylated skipped dienes from readily available $\mathrm{B}_{2} \mathrm{pin}_{2}$ and a wide variety of alkynes and allylic carbonates. The reaction operates under relatively mild conditions and selectivity is governed by strict catalyst control.

Table 1. Optimization of the Synergistic Cu/Pd-Catalyzed Allylboration of Alkynes

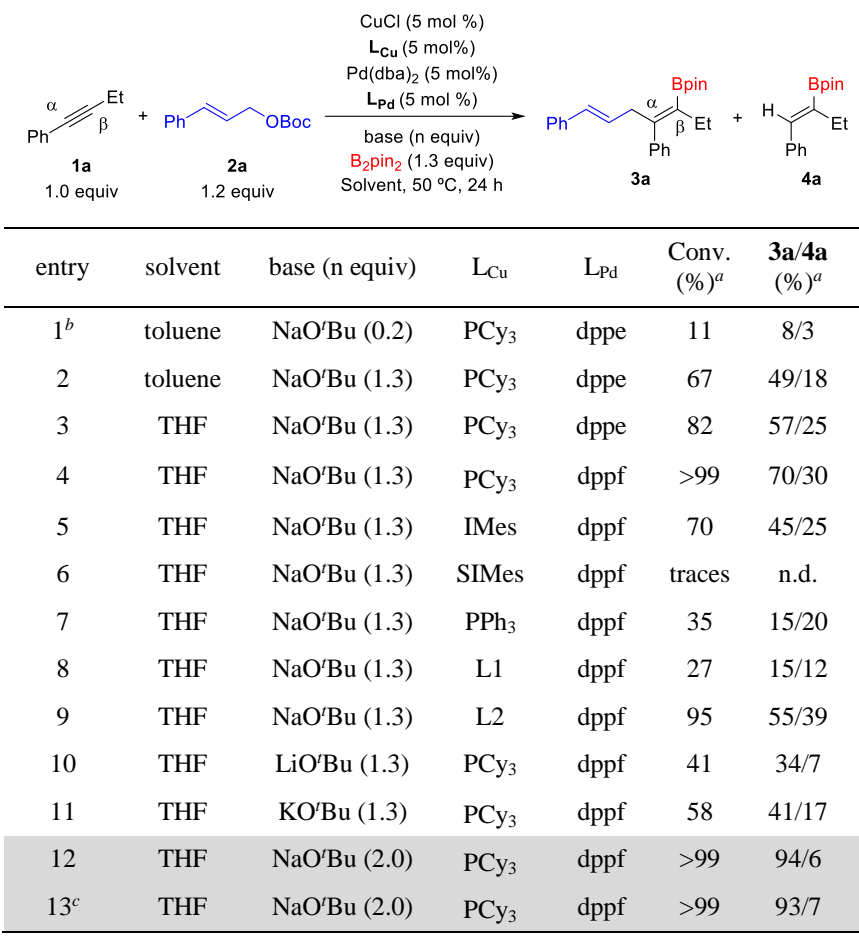

Reactions performed on a $0.2 \mathrm{mmol}$ scale $(0.1 \mathrm{M}) . \alpha / \beta$ and $\mathrm{S}_{\mathrm{N}} 2 / \mathrm{S}_{\mathrm{N}} 2^{\prime}>99: 1$ in all cases. ${ }^{a}$ Determined by ${ }^{1} \mathrm{H}-\mathrm{NMR}$ using $\mathrm{Ph}_{3} \mathrm{CH}$ as internal standard. ${ }^{b} 10 \mathrm{~mol} \%$ of both catalysts. ${ }^{c}$ Cinnamyl methyl carbonate used instead of 2a. dppe $=1,2$-bis (diphenylphosphinoethane). dppf $=1,1$ '-bis (diphenylphosphinoferrocene $) . \mathbf{L 1}=\mathrm{P}(o \text {-tolyl })_{3}$ $\mathbf{L 2}=\mathrm{P}\left(p \text {-OMe- } \mathrm{C}_{6} \mathrm{H}_{4}\right)_{3}$. IMes $=1,3$-dimesitylimidazolidinium chloride. SIMes $=1,3$ bis(mesityl)imidazolium chloride. n.d. = not determined

At the outset of our investigation, we selected a reaction involving $\mathrm{B}_{2}$ pin 2 , 1-phenyl-1-butyne (1a) and tert-butyl cinnamyl carbonate (2a) to evaluate both the feasibility and selectivity of the process (Table 1 and Supporting Information, Tables S1-S6). Initial experiments demonstrated that a stoichiometric amount of base is required to achieve good level of conversion (entries 1 and 2). ${ }^{19}$ Remarkably, these preliminary results already showed the great selectivity of the proposed strategy as 3a was obtained as a single isomer (out of the eight possible isomers arising from syn vs. anti borylcupration, $\alpha$ vs. $\beta$ allylation of the alkyne and $\mathrm{S}_{\mathrm{N}} 2$ vs. $\mathrm{S}_{\mathrm{N}} 2$ ' allylic substitution), with the alkyne hydroboration product $\mathbf{4 a}$ being the only side product. As hypothesized in our proposed mechanism, 3a was the result of a syn-selective borylcupration and an $\alpha$ - and $\mathrm{S}_{\mathrm{N}} 2$ selective allylation. Evaluation of different solvents (entries 23 and Table S1), palladium catalysts (entries 3-4 and Table S2), copper complexes (entries 4-9 and Table S3) and bases (entries 10-11 and Table S4) revealed that the combination of $\mathrm{CuCl} / \mathrm{PCy}_{3}, \mathrm{Pd}(\mathrm{dba})_{2} / \mathrm{dppf}, \mathrm{NaO}^{t} \mathrm{Bu}$ in THF is the most efficient system for this transformation (entry 4). Moreover, an increase in the amount of $\mathrm{NaO}^{t} \mathrm{Bu}$ (2.0 equiv) afforded $\mathbf{3 a}$ in an excellent $94 \%$ NMR yield almost precluding the formation of $\mathbf{4 a}$ (entry 12). Importantly, no formation of 3a was observed in the absence of either copper or palladium catalysts (Table S6). As expected cinnamyl methyl carbonate provided comparable results to those obtained with $\mathbf{2 a}$ under the optimized conditions (entry 13). On the other hand, cinnamyl phosphate, acetate and bromide were not efficient substrates for this transformation (Table S5).

Having established the optimized conditions for the $\mathrm{Cu} / \mathrm{Pd}$ catalyzed allylboration of alkynes (Table 1, entry 12), we set out to investigate the scope of the reaction. First, we explored this new transformation by using different alkynes 1 (Table 2).

Table 2. Scope of alkynes $^{a}$

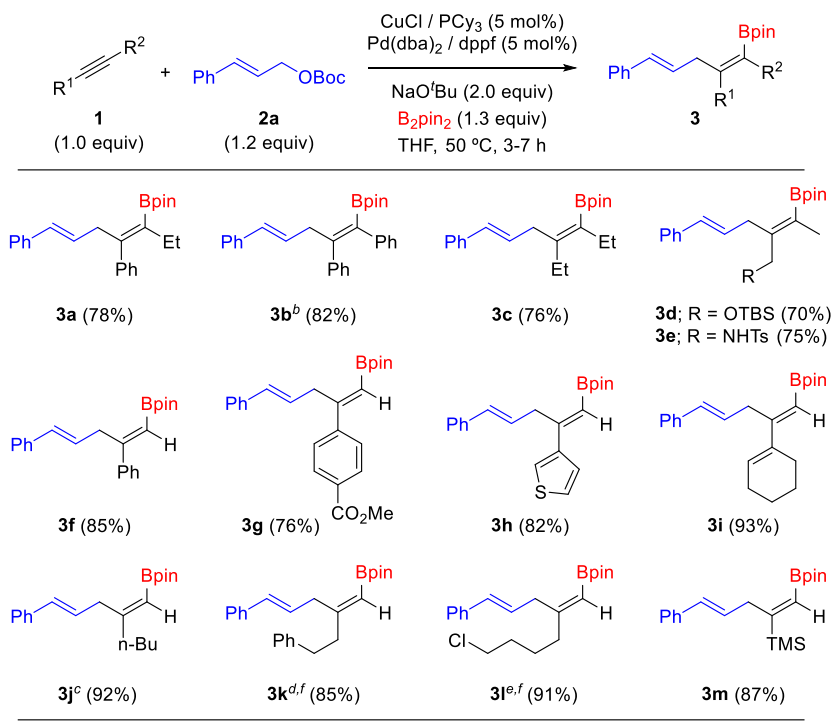

${ }^{a}$ Reactions performed on a $0.5 \mathrm{mmol}$ scale. $\alpha / \beta$ and $\mathrm{S}_{\mathrm{N}} 2 / \mathrm{S}_{\mathrm{N}} 2$ ratios $>99: 1$ unless otherwise noted. Yields refer to isolated pure products. Regioselectivity determined by GC and ${ }^{1} \mathrm{H}-\mathrm{NMR}$ analysis of the reaction crude. ${ }^{b}$ Structure was confirmed by $\mathrm{X}$ ray analysis. ${ }^{c} \alpha / \beta=95: 5 .{ }^{d} \alpha / \beta=90: 10 .{ }^{e} \alpha / \beta=82: 18 .{ }^{f}$ Combined yield of both $\alpha$ and $\beta$ regioisomers. For a list of alkynes 1, see Supporting Information page S4.

Reactions proceeded with total stereo- and regioselectivity and furnished exclusively the corresponding dienes $\mathbf{3}$ in nearly all cases. Moreover, several functional groups such as silyloxy, sulfonamide, chloro, ester and trimethylsilyl groups were well tolerated. Internal alkynes bearing both aromatic or aliphatic substituents proved to be very efficient substrates affording the corresponding products 3a-e in very good yields. Interestingly, dialkylalkynes $\mathbf{1 d}$ and 1e without a strong electronic bias ${ }^{7 \mathrm{~d}}$ to control the borylcupration step exhibited complete regioselectivity. Terminal alkynes were also efficient partners for this transformation despite the acidity of the terminal proton. Aryl and heteroaryl-substituted alkynes 1f-h and enyne $\mathbf{1 i}$ gave rise to the corresponding products $\mathbf{3 f}-\mathbf{i}$ in very good yields without any trace of the corresponding hydroboration products. Remarkably, alkyl-substituted terminal alkynes, which exhibited poor regioselectivity in copper-catalyzed allylboration $^{12}$ and alkylboration ${ }^{8 b}$ reactions, showed high levels of selectivity under our dual $\mathrm{Cu} / \mathrm{Pd}$ catalytic conditions. Borylated diene 3j was obtained from 1-hexyne with near perfect selectivity in $92 \%$ yield. The presence of a phenyl or a chloro group in the alkyl substituent caused a slight decrease on the $\alpha / \beta$ selectivity but products $3 \mathbf{k}$ and $3 \mathbf{l}$ were still obtained in good yields with perfect $\mathrm{S}_{\mathrm{N}} 2$ selectivity. Noteworthy is the reaction with trimethylsilylacetylene ${ }^{20}$ which gives stereoselective access to dienes (3m) featuring Bpin and TMS substituents which allow for further orthogonal functionalization of the diene. 
Different allyl carbonates were evaluated under the standard conditions (Table 3).

Table 3. Scope of allyl substrates ${ }^{a}$

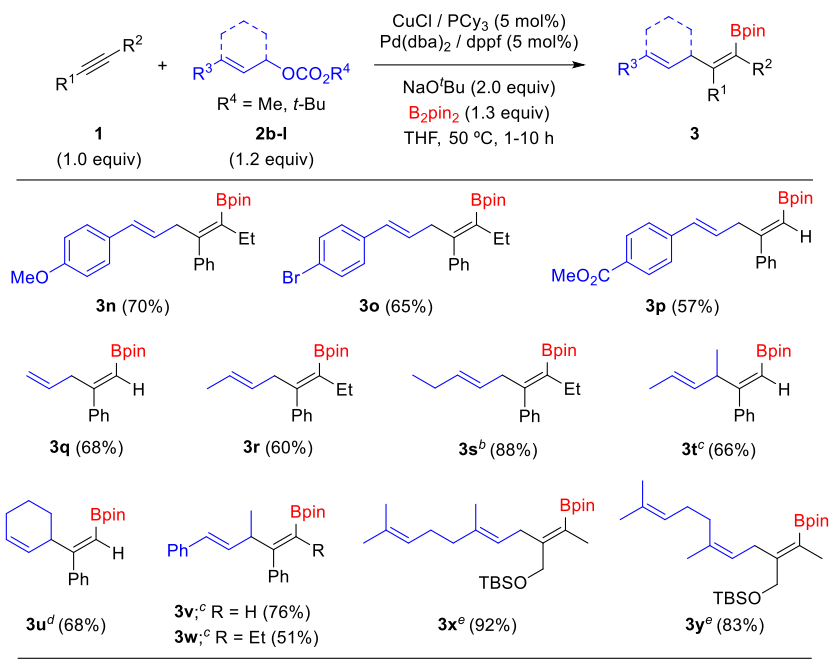

${ }^{a}$ Reactions performed on a $0.5 \mathrm{mmol}$ scale. $\alpha / \beta$ and $\mathrm{S}_{\mathrm{N}} 2 / \mathrm{S}_{\mathrm{N}} 2$ ' ratios $>99: 1$ in all cases. Yields refer to isolated pure products. Regioselectivity determined by ${ }^{1} \mathrm{H}-\mathrm{NMR}$ analysis of the reaction crude. ${ }^{b}(\mathrm{Z})-2 \mathrm{~g}$ used at $60{ }^{\circ} \mathrm{C}$. ${ }^{c} \mathrm{In}$ toluene at $50{ }^{\circ} \mathrm{C}$. ${ }^{d}$ In toluene at $75{ }^{\circ} \mathrm{C}$. ${ }^{\mathrm{T}} \mathrm{THF}$ reflux using 1.1 equiv of $\mathrm{B}_{2} \mathrm{pin}_{2}$. For a list of alkynes $\mathbf{1}$ and allyl carbonates 2, see Supporting Information page S4.

Both electron-rich and electron-deficient cinnamyl substrates worked well and afforded products 3n-p in good yields with perfect $\alpha$ and $\mathrm{S}_{\mathrm{N}} 2$ selectivity. Remarkably, in the case of 3o, the catalytic system tolerated the presence of an aromatic bromide. There was no evidence of borylation of the aryl bromide $^{21}$ thus demonstrating the extremely high chemoselectivity of this dual catalytic system. Terminal and aliphatic allyl carbonates were also suitable substrates for this transformation showing good reactivity with both terminal and internal alkynes (3q-s). When (Z)-tert-butyl pent-2-en-1-yl carbonate $\mathbf{2 g}$ was used, inversion of the configuration of the allyl double bond took place and the corresponding diene $3 \mathbf{s}$ was obtained as pure $(Z, E)$ isomer. $^{22}$ The reaction was also compatible with the use of secondary cyclic and acyclic allylic carbonates (3tw) with toluene being the most efficient solvent in these cases. Interestingly, complete $S_{N} 2$ selectivity was still observed in the formation of dienes $\mathbf{3 v}$ and $\mathbf{3 w}$ from unsymmetrical secondary allyl carbonate $\mathbf{2} \mathbf{j}$. The use of tri-substituted allylic carbonates was exemplified by using geraniol (2k) and nerol (2l) derivatives. In both cases the corresponding products $3 \mathbf{x}$ and $3 y$ were obtained in excellent yield and with complete regio- and stereoselectivity and total retention of the configuration of the double bond of the starting allylic substrate. ${ }^{23}$ These results show that synergistic $\mathrm{Cu} / \mathrm{Pd}$ catalysis allows for an efficient allylboration of alkynes which features total $\mathrm{S}_{\mathrm{N}} 2$ type regioselectivity enabled by the $\mathrm{Pd}$ catalytic cycle. This is in sharp contrast with the recently reported copper-catalyzed allylboration of alkynes with allyl phosphates ${ }^{12}$ in which regioselectivity is governed by substrate control and formal $S_{N} 2$ or $\mathrm{S}_{\mathrm{N}} 2$ 'substitution products, or mixtures of both, are obtained depending on the nature of the alkyne and the allyl phosphate.

To illustrate the synthetic utility of the present catalytic methodology, we targeted the synthesis of two natural products (Scheme 2). (Z,E)- $\alpha$-Homofarnesene 5, a component of the trail pheromone of the fire-ant, ${ }^{24}$ could be obtained in two steps via $\mathrm{Cu} / \mathrm{Pd}$-catalyzed allylboration of 2-butyne 1 n with allyl carbonate $\mathbf{2 k}$ and subsequent Suzuki coupling with vinyl bromide (Scheme 2a). This new synthetic route reduces significantly the number of steps and provides a single stereoisomer in contrast to previous syntheses which afforded mixtures of the $(Z, E)$ and $(E, E)$ homofarnesenes. ${ }^{24 \mathrm{~b}, \mathrm{c}}$

Scheme 2. Synthetic applications

a) Synthesis of $\alpha-(Z, E)$-homofarnesene (5)

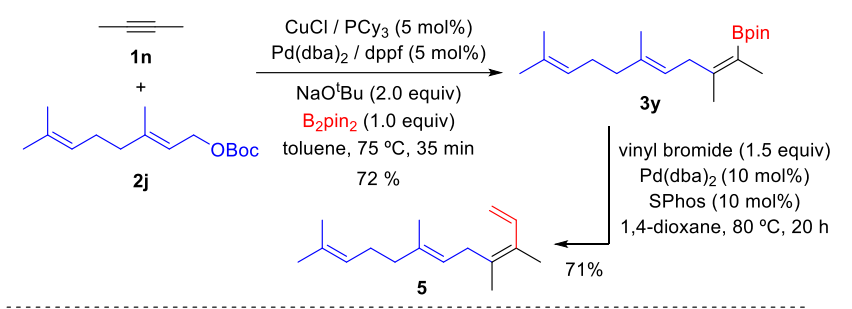

b) Synthesis of isosesquilavandulyl alcohol (7) TBSO

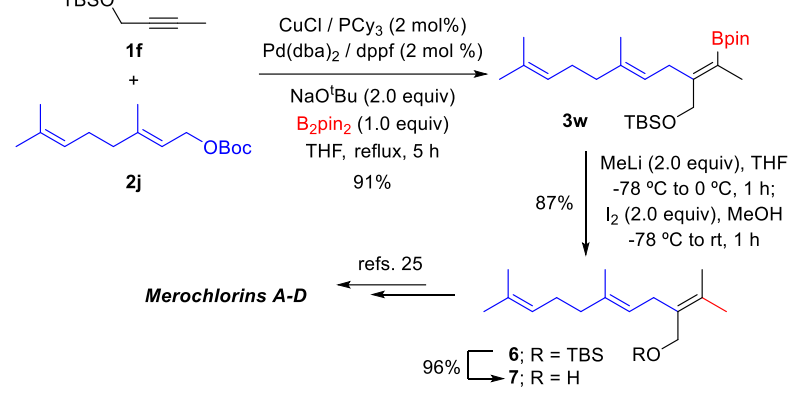

We also applied our methodology to the synthesis of isosesquilavandulyl alcohol 7 (Scheme 2b), a key intermediate in the synthesis of Merochlorins A-D which are marine meroterpenoid secondary metabolites with potent antibiotic activity. ${ }^{25}$ Synthesis of $\mathbf{3 x}$ was executed on larger scale $(3 \mathrm{mmol})$ using a reduced catalyst loading ( $2 \mathrm{~mol} \%$ of both copper and palladium catalysts) and still furnished the product without erosion of yield (92\%). Conversion of the $\mathrm{C}$-Bpin to a $\mathrm{C}-\mathrm{Me}$ bond was performed by reaction with MeLi and iodine, ${ }^{26}$ affording 6 in $87 \%$ yield. Final cleavage of the TBS group delivered isosesquilavandulyl alcohol 7 in $77 \%$ overall yield. This route not only gives straightforward access to 7 but also offers the possibility of synthesizing artificial analogs of Merochlorins by alternative functionalization (e.g. trifluoromethylation, fluorination) of the C-Bpin bond.

In summary, we have described a synergistic $\mathrm{Cu} / \mathrm{Pd}$ catalyzed three-component reaction of alkynes, $\mathrm{B}_{2} \mathrm{pin}_{2}$ and allyl carbonates. This transformation represents the first example of the use of catalytically generated $\beta$-borylalkenylcopper species in Pd-catalyzed allylic substitution. The reaction affords borylated skipped dienes from good to excellent yields with a remarkable regio-, stereo- and chemoselectivity. The synthetic potential of this method has been illustrated by the syntheses of naturally occurring $(Z, E)-\alpha$ homofarnesene and isosesquilavandulyl alcohol from simple starting materials. Mechanistic studies, development of an enantioselective version and extension to related systems are in progress.

\section{ASSOCIATED CONTENT}

Supporting Information. List of substrates, optimization tables, experimental procedures, and characterization data. This material is available free of charge via the Internet at http://pubs.acs.org.

\section{AUTHOR INFORMATION}

\section{Corresponding Author}


* martin.fananas@usc.es

\section{ACKNOWLEDGMENT}

Financial support from MINECO (RYC-2012-11749; CTQ201562724-ERC), BBVA Foundation (IN[15]_CBB_QUI_3065), Xunta de Galicia (ED431F 2016/006; GRC2014/032; Centro singular de investigación de Galicia accreditation 2016-2019, ED431G/09) and ERDF is gratefully acknowledged. M. F.-M. is grateful to MINECO for a Ramón y Cajal contract. E. R.-C. thanks Segundo Gil Dávila Foundation for a predoctoral fellowship.

\section{REFERENCES}

(1) (a) Jie, M. S. F. L. K.; Pasha, M. K.; Syed-Rahmatulla, M. S. K.; Nat. Prod. Rep. 1997, 14, 163-189. (b) Fürstner, A.; Nevado, C.; Waser, M.; Tremblay, M.; Chevrier, C.; Teplý, F.; Aïssa, C.; Moulin, E.; Müller, O. J. Am. Chem. Soc. 2007, 129, 9150-9161. (c) Wilson, M. C.; Nam, S.-J.; Gulder, T. A. M.; Kauffman, C. A.; Jensen, P. R.; Fenical, W.; Moore, B. S.; J. Am. Chem. Soc. 2011, 133, 1971-1977.

(2) (a) Macklin, T. K.; Micalizio, G. C. Nat. Chem. 2010, 2, 638643. (b) Sharma, R. K.; RajanBabu, T. V. J. Am. Chem. Soc., 2010, 132, 3295-3297. (c) Matsubara R.; Jamison, T. F. J. Am. Chem. Soc., 2010, 132, 6880-6881. (d) Ye, K.-Y.; He, H.; Liu, W.-B.; Dai, L.-X.; Helmchen, G.; You, S.-L. J. Am. Chem. Soc. 2011, 133, 1900619014. (e) Huang, Y.; Fañanás-Mastral, M.; Minnaard, A. J.; Feringa, B. L. Chem. Commun. 2013, 49, 3309-3311. (f) McCammant, M. S.; Liao, L.; Sigman, M. S. J. Am. Chem. Soc. 2013, 135, 4167-4170. (g) Todd, D. P.; Thompson, B. B.; Nett, A. J.; Montgomery, J. J. Am. Chem. Soc. 2015, 137, 12788-12791.

(3) (a) Miyaura, N.; Yano, T.; Suzuki, A. Tetrahedron Lett. 1980, 21, 2865-2868. (b) Matsushita, H.; Negishi, E. J. Am. Chem. Soc. 1981, 103, 2882-2884. (c) Sheffy, F. K.; Stille, J. K. J. Am. Chem. Soc. 1983, 105, 7173-7175. (d) Kabalka, G. W.; Al-Masum, M. Org. Lett. 2006, 8, 11-13.

(4) (a) Lee, Y.; Akiyama, K.; Gillingham, D. G.; Brown, M. K.; Hoveyda, A. H. J. Am. Chem. Soc. 2008, 130, 446-447. (b) Akiyama, K.; Gao, F.; Hoveyda, A. H. Angew. Chem., Int. Ed. 2010, 49, 419423. (c) Gao, F.; McGrath, K. P.; Lee, Y.; Hoveyda, A. H. J. Am. Chem. Soc. 2010, 132, 14315-14320. (d) Gao, F.; Carr, J. L.; Hoveyda, A. H. Angew. Chem., Int. Ed. 2012, 51, 6613-6617. (e) Gao, F.; Carr, J. L.; Hoveyda, A. H. J. Am. Chem. Soc. 2014, 136, $2149-2161$. (f) Sidera, M.; Fletcher, S. P. Chem. Commun. 2015, 51, 5044-5047. (g) Zhurkin, F. E.; Hu, X. J. Org. Chem. 2016, 81, 5795-5802.

(5) Hamilton, J. Y.; Sarlah, D.; Carreira, E. M. J. Am. Chem. Soc. 2013, 135, 994-997.

(6) (a) Takahashi, K.; Ishiyama, T.; Miyaura, N. J. Organomet. Chem. 2001, 625, 47-53. For reviews, see: (b) Semba, K.; Fujihara, T.; Terao, J.; Tsuji, Y. Tetrahedron 2015, 71, 2183-2197. (c) Yoshida, H. ACS Catal. 2016, 6, 1799-1811.

(7) For selected examples, see: (a) Jang, H.; Zhugralin, A. R.; Lee, Y.; Hoveyda, A. H. J. Am. Chem. Soc. 2011, 133, 7859-7871. (b) Kim, H. R.; Yun, J. Chem. Commun. 2011, 47, 2943-2945. (c) Moure, A. L.; Gómez Arrayás, R.; Cárdenas, D. J.; Alonso, I.; Carretero, J. C. J. Am. Chem. Soc. 2012, 134, 7219-7222. (d) Park, J. K.; Ondrusek, B. A.; McQuade, D. T. Org. Lett. 2012, 14, 4790-4793. (e) Moure, A. L.; Mauleón, P.; Arrayás, R. G.; Carretero, J. C. Org. Lett. 2013, 15, 2054-2057.

(8) For Cu-catalyzed alkylboration of alkynes: (a) Alfaro, R.; Parra, A.; Alemán, J.; García Ruano, J. L.; Tortosa, M. J. Am. Chem. Soc. 2012, 134, 15165-15168. (b) Yoshida, H.; Kageyuki, I.; Takaki, K. Org. Lett. 2013, 15, 952-955. (c) Kubota, K.; Iwamoto, H.; Yamamoto, E.; Ito, H. Org. Lett. 2015, 17, 620-623. (d) Su, W.; Gong, T.-J.; Zhang, Q.; Zhang, Q.; Xiao, B.; Fu, Y. ACS Catal. 2016, 6, 64176421. (e) Itoh, T.; Shimizu, Y.; Kanai, M. J. Am. Chem. Soc. 2016, 138, 7528-7531.

(9) For Cu-catalyzed arylboration of alkynes: Zhou, Y.; You, W.; Smith, K. B.; Brown, M. K. Angew. Chem., Int. Ed. 2014, 53, 34753479 .
(10) For Cu-catalyzed carboxaboration of alkynes: Zhang, L; Cheng, J.; Carry, B.; Hou, Z. J. Am. Chem. Soc. 2012, 134, 1431414317.

(11) For Cu-catalyzed borylative cyclization of alkynes: Liu, P.; Fukui, Y.; Tian, P.; He, Z.-T.; Sun, C.-Y.; Wu, N.-Y.; Lin, G.-Q. J. Am. Chem. Soc. 2013, 135, 11700-11703.

(12) For Cu-catalyzed allylboration of alkynes: Bin, H.-Y.; Wei, X.; Zi, J.; Zuo, Y.-J.; Wang, T.-C.; Zhong, C.-M. ACS Catal. 2015, 5, 6670-6679.

(13) For reviews on synergistic catalysis, see: (a) Allen, A. E.; MacMillan, D. W. C. Chem. Sci. 2012, 3, 633-658. (b) Pye, D. R.; Mankad, N. P. Chem. Sci. 2017, 8, 1705-1718. For examples of cooperative bimetallic catalysis involving Pd-catalyzed allylic substitution, see: (c) Sawamura, M.; Sudoh M.; Ito, Y.; J. Am. Chem. Soc. 1996, 118, 3309-3310. (d) Trost, B. M.; Luan, X.; Miller, Y. J. Am. Chem. Soc. 2011, 133, 12824-12833. (e) Vercruysse, S.; Cornelissen, L.; Nahra, F.; Collard, L.; Riant, O. Chem. - Eur. J 2014, 20, 1834-1838. (f) Chen, Z.-S.; Huang, L.-Z.; Jeon, H. J.; Xuan, Z.; Lee, S. ACS Catal. 2016, 6, 4914-4919.

(14) For $\mathrm{Cu} / \mathrm{Pd}$-catalyzed arylboration reactions: (a) Semba, K.; Nakao, Y. J. Am. Chem. Soc. 2014, 136, 7567-7570. (b) Smith, K. B.; Logan, K. M.; You, W.; Brown, M. K. Chem. - Eur. J. 2014, 20, 12032-12036. (c) Logan, K. M.; Smith, K. B.; Brown, M. K. Angew. Chem., Int. Ed. 2015, 54, 5228-5231. (d) Logan, K. M.; Brown, M. K. Angew. Chem., Int. Ed. 2017, 56, 851-855. (e) Chen, B.; Cao, P.; Yin, X.; Liao, Y.; Jiang, L.; Ye, J.; Wang, M.; Liao, J. ACS Catal. 2017, 7, 2425-2429. (f) Smith, K. B.; Brown, M. K. J. Am. Chem. Soc. 2017, $139,7721-7724$.

(15) For Cu/Pd-catalyzed allylboration of styrenes: Jia, T.; Cao, P.; Wang, B.; Lou, Y.; Yin, X.; Wang, M.; Liao, J. J. Am. Chem. Soc. 2015, 137, 13760-13763.

(16) (a) Trost, B. M.; Crawley, M. L. Chem. Rev. 2003, 103, 29212943. (b) Poli, G.; Prestat, G.; Liron, F.; Kammerer-Pentier, C. Top. Organomet. Chem. 2012, 34, 1-64.

(17) (a) Ito, H.; Kawakami, C.; Sawamura, M. J. Am. Chem. Soc. 2005, 127, 16034-16035. (b) Ito, H.; Ito, S.; Sasaki, Y.; Matsuura, K.; Sawamura, M. J. Am. Chem. Soc. 2007, 129, 14856-14857. (c) Guzman-Martinez, A.; Hoveyda, A. H. J. Am. Chem. Soc. 2010, 132, 10634-10637.

(18) (a) Ishiyama, T.; Ahiko, T.; Miyaura, N. Tetrahedron Lett. 1996, 37, 6889-6892. (b) Dutheuil, G.; Selander, N.; Szabó, K. J.; Aggarwal, V. K. Synthesis 2008, 2293-2297. (c) Zhang, P.; Roundtree, I. A.; Morken, J. P. Org. Lett. 2012, 14, 1363-1419.

(19) As the use of allyl carbonate 2a would facilitate the regeneration of $\mathrm{LCuO}^{t} \mathrm{Bu}$ after the allylation event, the requirement of a stoichiometric amount of base might be due to the formation of a more reactive alkenylcuprate from alkenylcopper species III by reaction with $\mathrm{NaO}^{t} \mathrm{Bu}$. For a proposed alkenylcuprate intermediacy in coppercatalyzed carboboration reactions see refs. $6 \mathrm{c}$ and $8 \mathrm{~b}$.

(20) Trimethylsilylacetylene has shown to be a reluctant partner in copper-catalyzed allylboration (ref. 12) and hydroboration reactions: Chae, Y. M.; Bae, J. S.; Moon, J. H.; Lee, J. Y.; Yun, J. Adv. Synth. Catal. 2014, 356, 843-849.

(21) Ishiyama, T.; Murata, M.; Miyaura, N. J. Org. Chem. 1995, 60, 7508-7510.

(22) Inversion of the allyl double bond configuration might arise from $\pi-\sigma$ isomerization and C-C bond rotation of the allyl-Pd(II) intermediate.

(23) Stereochemical retention of the double bond geometry would be the result of a slow $\pi-\sigma-\pi$ isomerization of the corresponding trisubstituted allyl-Pd(II) intermediate.

(24) (a) Wilson, E.O. Science 1959, 129, 643-644. (b) Alvarez, F. M.; Vander Meer, R. K.; Lofgren, C. S. Tetrahedron 1987, 43, $2897-$ 2900. (c) Chou, S.-S. P.; Lee, W.-H. Synthesis 1990, 219-220.

(25) (a) Kaysser, L.; Bernhardt, P.; Nam, S.-J.; Loesgen, S.; Ruby, J. G.; Skewes-Cox, P.; Jensen, P. R.; Fenical, W.; Moore, B. S. J. Am. Chem. Soc. 2012, 134, 11988-11991. (b) Pepper, H. P.; George, J. H. Angew. Chem., Int. Ed. 2013, 52, 12170-12173. (c) Meier, R.; Strych, S.; Trauner, D. Org. Lett. 2014, 16, 2634-2637. (d) Teufel, R.; Kaysser, L.; Villaume, M. T.; Diethelm, S.; Carbullido, M. K.; Baran, P. S.; Moore, B. S. Angew. Chem., Int. Ed. 2014, 53, 11019-11022. 
(26) (a) Xu, S.; Lee, C.-T.; Rao, H.; Negishi, E. Adv. Synth. Catal. 2011, 353, 2981-2987. (b) Meng, F.; McGrath, K. P.; Hoveyda, A. H. Nature 2014, 513, 367-374. 


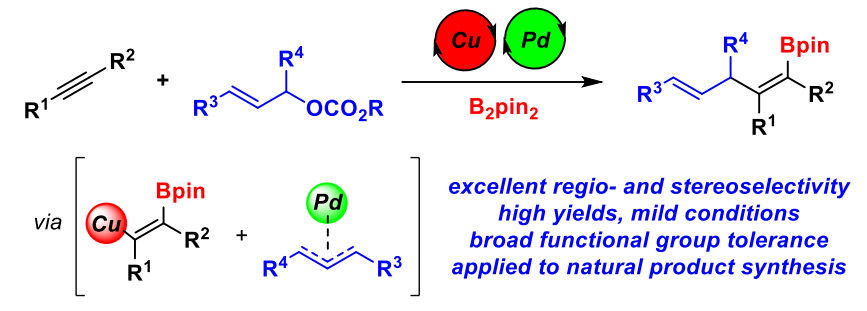

